\title{
Optical Characterization of SERS Substrates Based on Porous Au Films Prepared by Pulsed Laser Deposition
}

\author{
V. V. Strelchuk, O. F. Kolomys, E. B. Kaganovich, I. M. Krishchenko, \\ B. O. Golichenko, M. I. Boyko, S. O. Kravchenko, I. V. Kruglenko, O. S. Lytvyn, \\ E. G. Manoilov, and Iu. M. Nasieka
}

V.E. Lashkarev Institute of Semiconductor Physics, NAS of Ukraine, 45 Nauki Avenue, Kyiv 03028, Ukraine

Correspondence should be addressed to Iu. M. Nasieka; yunaseka@gmail.com

Received 12 November 2014; Accepted 7 March 2015

Academic Editor: Benxia Li

Copyright (C) 2015 V. V. Strelchuk et al. This is an open access article distributed under the Creative Commons Attribution License, which permits unrestricted use, distribution, and reproduction in any medium, provided the original work is properly cited.

\begin{abstract}
The SERS (surface enhanced Raman spectroscopy) substrates based on nanocomposite porous films with gold nanoparticles (Au NPs) arrays were formed using the method of the pulsed laser deposition from the back low-energy flux of erosion torch particles on the glass substrate fixed at the target plain. The dependencies of porosity, and morphology of the surface of the film regions located near and far from the torch axis on the laser ablation regime, laser pulses energy density, their number, and argon pressure in the vacuum chamber, were ascertained. The Au NPs arrays with the controllable extinction spectra caused by the local surface plasmon resonance were prepared. The possibility of the formation of SERS substrates for the detection of the Rhodamine $6 \mathrm{G}$ molecules with the concentration $10^{-10} \mathrm{Mol} / \mathrm{L}$ with the enhancement factor $4 \cdot 10^{7}$ was shown.
\end{abstract}

\section{Introduction}

Surface enhanced Raman spectroscopy (SERS) is highly efficient and sensitive technique for the detection of analytes (substance or chemical constituent) at extremely low concentrations [1-6]. The SERS has very important applications in areas, such as medicine, catalysis, industrial applications, and scientific investigation. In SERS, the Raman signal of the probe molecule, is amplified through excitation of localized surface plasmon resonance (LSPR) of the substrate, usually in the form of metal particles or a roughened metal film. There are two primary mechanisms of enhancement described in the literature: an electromagnetic and a chemical enhancement. The electromagnetic effect is dominant, with the chemical effect contributing enhancement only on the order of an order or two of magnitude. The electromagnetic enhancement (EME) is dependent on the presence of the metal surface's roughness features, while the chemical enhancement (CE) involves changes to the adsorbate electronic states due to chemisorption of the analyte. The chemical theory applies only for species that have formed a chemical bond with the surface, so it cannot explain the observed signal enhancement in all cases, whereas the electromagnetic theory can apply even in those cases where the specimen is physisorbed only to the surface [4-11]. SERS for many analytes is determined by electromagnetic mechanism. Under the laser excitation of metal (gold or silver nanoparticles (NPs)) the local surface plasmon resonance occurs. The local electric field near the $\mathrm{Au}(\mathrm{Ag})$ NPs enhances; enhancement of the scattering by the analyte which located near the nanoparticles occurs too. The enhancement coefficient chiefly depends on the plasmon properties of $\mathrm{Au}(\mathrm{Ag})$ NPs. Numerous methods have been reported for preparing effective SERS substrates, for example, electron-beam lithography and focused ion-beam milling, evaporation or pulsed laser deposition (PLD) of metallic NPs, roughened metal electrodes, acid-etching of metal foil, iodination of evaporated silver foil, replication method of polymer surfaces, nanosphere lithography, step-by-step assembly of NP multilayers, and metal nanoshells [12-14]. Among these methods, metal NPs are one of the most popular materials owing to the strong enhancement, convenient preparation, and high surface area of the absorbing species. There are many SERS applications in the biosensing field, from DNA to proteins to cells. Also, biotemplating methods 
to anchor metal NPs for enhanced SERS have been reported $[4,15,16]$.

A special interest is caused corresponding to the formation of the porous films with NPs of gold and silver for SERS substrates due to their large internal surface for analyte and possibility of the formation of so-called "hot spots" in the pores (pores with high values of local electromagnetic fields) which mainly provide an enhancement in the light scattering by the analyte. It is well known about the porous nanocomposite systems that the walls of glass-ceramics pores, silicon, and aluminum oxides are covered by the films with plasmon NPs. Porous gold (por-Au) films for SERS substrates were prepared from the gold-silver alloy with the selective etching of the silver [17]. The fundamental metric for SERS activity is the enhancement factor (EF), which quantifies the increase in signal intensity (counts s ${ }^{-1} \mathrm{~mW}^{-1}$ ) per molecule. Commonly, EFs are within the range $10^{3}$ up to $10^{7}[2,6]$. One of the popular methods for Au and Ag NPs preparation is PLD method. The details of standard PLD method have been described in $[11,18,19]$.

In our previous works [20-22] by the method of pulsed laser deposition in vacuum the por-Au films were prepared. For these films the local surface plasmon resonance was observed. The aim of the present work is preparation and investigation of the SERS substrates for Rhodamine $6 \mathrm{G}$ on the base of these films.

\section{Methods}

Recently, unporous films with Au NPs array for SERS were prepared by the PLD method from the direct high-energy flux of erosion torch particles on the substrate which is placed on the distance along the normal to the target plain [23]. Distinctive feature of the PLD method which we use for the preparation of porous films with Au NPs array is deposition of the Au NPs from the back low-energy flux of erosion torch particles on the substrate placed at the target plain.

In our scheme of the films deposition the gold target was scanned by the beam of YAG: $\mathrm{Nd}^{3}$ laser $(\lambda=1.06 \mu \mathrm{m}$, $E_{i}=0.2 \mathrm{~J}, \tau_{p}=10 \mathrm{~ns}$, and $\left.f_{p}=25 \mathrm{~Hz}\right)$ in the argon atmosphere with the pressure $\mathrm{P}_{\mathrm{Ar}}$ within the range 10 up to $100 \mathrm{~Pa}$. The energy fluence was about $5 \cdots 20 \mathrm{~J} / \mathrm{cm}^{2}$. The exposition time was varied from 3 to 30 minutes which corresponds to the pulses numbers $4500 \cdots 45000$. In the torch an interaction between $\mathrm{Au}$ atoms with gas atoms occurs before the Au NPs (clusters) formation. The quantity of the atoms in mentioned clusters depends on the deposition parameters (energy fluence, number of the pulses, and argon pressure). The substrate was positioned in the target plane; film deposition was provided from the back flux of lowenergy particles from the torch as a result of its energy scattering on the gas atoms; see Figure 1 (insertion). One can see that corresponding conditions differ from the traditional preparation of nonporous films by the deposition from the direct flux of high-energy particles. Exactly, the above-mentioned preparation peculiarities provide porous films growth. Under such conditions, the NPs of large sizes chiefly were deposited on the film regions fixed near the torch axis. The NPs of small

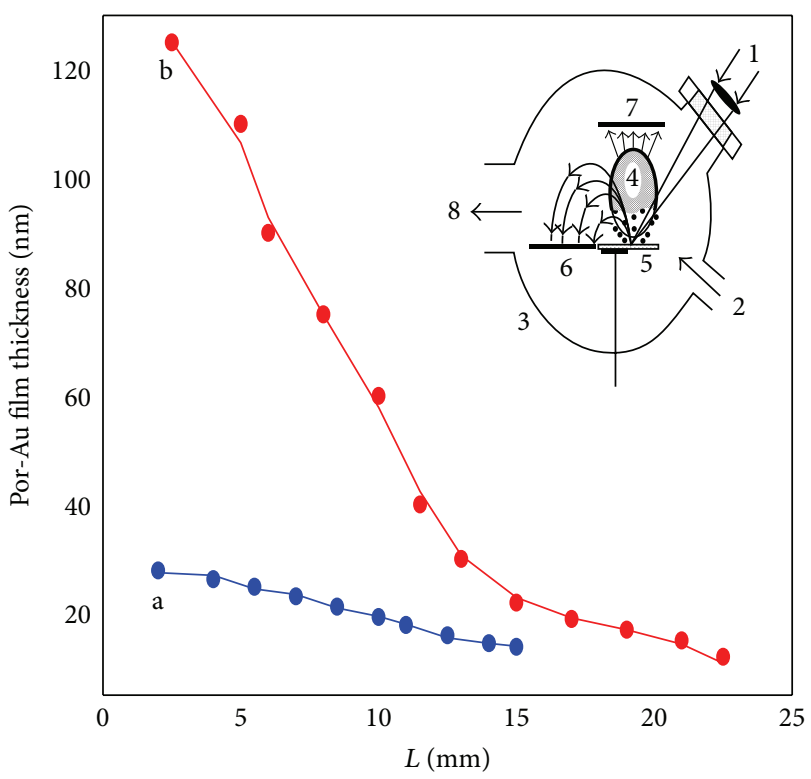

Figure 1: The dependencies of the por-Au films thicknesses on the distance from the film point to the erosion torch axis $(L)$ : (a) argon pressure $13.5 \mathrm{~Pa}$ and (b) $100 \mathrm{~Pa}$. The corresponding one pulse energy was $5 \mathrm{~J} / \mathrm{cm}^{2}$ and the number of laser pulses $N=30000$. In the insertion the scheme of the vacuum PLD equipment set is presented: (1) laser beam, (2) gas flux, (3) vacuum chamber, (4) erosion torch, (5) target, $(6,7)$ substrates, and (8) vacuum pump.

sizes were deposited on distance from the torch axis. Also, the porosity changes along the film. Therefore, the parameter which indicates the dot location relatively to the torch axis (assigned L) influences the structural and optical properties of the films. The developed method provides gradient of the por-Au film thickness, NPs sizes, and distances between them as well as pore sizes. Consequently, an optimal size for the analyte detection can be simply determined correspondingly to the SERS signal intensity in the fixed film point.

An investigation of the films thickness and surface morphology was carried out by the method of scanning atomic force microscopy (AFM) using microscope Nanoscope IIIa (Digital Instruments) in the periodical contact regime. Si probes with nominal tip radii of $10 \mathrm{~nm}$ were used. Structural parameters and films thickness were determined in the dependency on the film point location from the erosion torch axis and on the technological parameters of the deposition. Vertical and horizontal sizes of Au NPs and pores were evaluated. Also, distribution histogram of their sizes was plotted.

The porosity evaluation of the por-Au films was carried out using the method of quartz microweighting. At the equal area of the substrates points and taking into account their thickness and measuring the changes of the piezoelectric quartz resonator frequencies the density of controllable film regions on the substrate $\left(\rho_{\text {por }}\right)$ was determined. The porosity value $q$ was obtained from the equation

$$
q=\frac{\rho_{\text {bulk }}-\rho_{\text {por }}}{\rho_{\text {bulk }}},
$$

where $\rho_{\text {bulk }}$ is the density of "nonporous bulk gold" (19.3 g/ $\mathrm{cm}^{3}$ ). 
The transmittance spectra of the films were measured using the spectrophotometer SF-26 within the spectral range $360 \cdots 1000 \mathrm{~nm}$ at once after formation and after keeping them at the air.

The samples for measuring the SERS spectra were substrates divided into three parts: on the first part the por- $\mathrm{Au}$ film was deposited, on the second part is the film of "nonporous" gold prepared by thermal evaporation in vacuum, and the third part was noncovered. The samples were put in the solution of Rhodamine $6 \mathrm{G}$ of the concentrations of $10^{-3} \cdots 10^{-10} \mathrm{Mol} / \mathrm{L}$ and held during one hour. After that the samples were dried at the air.

The SERS spectra were measured using the triple spectrometer Horiba Jobin Yvon T64000 equipped with confocal optical microscope. As an optical excitation source the Ar- Kr laser line with $\lambda_{\mathrm{ex}}=514.5 \mathrm{~nm}$ was used. The laser beam was focused on the sample surface in the spot with the diameter equal to $0.7 \mu \mathrm{m}$. The spatial mapping of the optical spectra of studied structures was carried out using the automatic moving of the table with the step $0.1 \mu \mathrm{m}$. The accuracy of the determination of the frequency of phonon bands was equal to $0.15 \mathrm{~cm}^{-1}$.

\section{Results and Discussion}

Figure 1 presents the profiles of the films thickness of the wedge-like shapes ascertained using the AFM measurements. With increase in the distance from the torch axis to $20 \mathrm{~mm}$ the films thickness decreases from hundreds to tenth nanometers in the mentioned formation conditions. The films thickness increases with increase of the argon pressure in the chamber, the number of pulses, and the energy fluence.

Figure 2 shows the AFM images of the por-Au film in five fixed points on the various distances from the erosion torch axis. Figure 3 displays the distribution of the seed and pores sizes correspondingly to the AFM images. An analysis of the surface morphology indicates the presence of the $\mathrm{Au}$ NPs array, their conglomerates, and pores with equal concentration. With increase in the distance from the erosion torch axis the decrease of the sizes of the Au NPs and pores was observed. From the showed histograms one can see that for every point of the film wedge the distribution character is wide and the seeds and pores sizes decrease with increase of the distance from the erosion torch axis. If near the axis of erosion torch the Au seeds sizes attain $60 \mathrm{~nm}$, then on the distance they are equal to $12 \mathrm{~nm}$. On the distance more than $12 \mathrm{~mm}$ the Au NPs and pores have similar sizes and near the erosion torch the pores are smaller by 2 times compared with the Au NPs.

The porosity evaluation by the method of quartz microweighting indicates that for the thin por-Au film (see Figure 1 , a) porosity increases from $\sim 60 \%$ up to $80 \%$ with the increase in the distance between substrate points and torch axis. It is important to note that the increase of the porosity with the distance between substrates points and the axis occurs for the small thicknesses of the films (equal to $40 \mathrm{~nm}$ ) which on the distance from the torch axis are granulated. In the same time on the closest points to the torch axis at the thicknesses equal to $30 \mathrm{~nm}$ the films are characterized by a higher density.

The spectra $T(\lambda)$ in the dependences on argon pressure in the operation chamber and on the substrate point location are shown on Figure 4. One can see the following peculiarities. Firstly, with the increase of the argon pressure from 13.5 up to $100 \mathrm{~Pa}$ the absorption increases (compare curves 1 and $1^{\prime}$ with curves 2 and $2^{\prime}$ ), moreover, for the closest substrate point to the torch axis it becomes more sharp (compare curves 1 and 2 with $1^{\prime}$ and $2^{\prime}$ ). Secondly, for the distant point the absorption is smaller than that for the closest one (compare curves $1^{\prime}$ and $2^{\prime}$ with curves 1 and 2) at any pressures. Thirdly, the spectra are wide, the positions of the minima of transmittance curves are located within the range of $560 \cdots 590 \mathrm{~nm}$, and for the distant point with the increase of the argon pressure the red-shift of the peak position of the transmittance band by $30 \mathrm{~nm}$ is observed (compare curves $1^{\prime}$ and $2^{\prime}$ ). The explanation of the features of the dependencies of the absorption spectra on the technological parameters (argon pressure and distance $L$ ) is as follows. With the increase of the argon pressure the torch size decreases which leads to enhancement in the interaction between Au atoms and increase in the Au clusters size in the torch. The red-shift in the absorption spectrum is more significant when the Au clusters size is larger. As we can see from Figure 4 the plasmonic properties in the spectra are best manifested for the closest point at the argon pressure $13.5 \mathrm{~Pa}$ and for the distant point under $P=100 \mathrm{~Pa}$. The wide transmittance spectra represent dispersion of the NPs sizes and shapes.

Figure 5 presents the SERS spectra registered in the substrate points on the various distances from the torch axis. The spectra have the typical bands for the molecules of Rhodamine. On the insertion the intensities of SERS signal for five points on the film are shown. One can see that with the increase in the distance from the point to the torch axis the intensity of the signal increases and has the maximum in point $3(L=12 \mathrm{~mm})$ and then for points 1 and $2(L=$ $17,22 \mathrm{~mm}$ ) decreases. The intensity of the signal in point 3 is larger by 2 times compared with other film points. The smaller signal intensity for the film points near the torch axis is caused by larger sizes of the Au NPs and pores (several tens of nanometers) compared with optimal ones. The smaller signal intensity for the most distant points is attributed with the smaller Au NPs sizes and the film thickness compared with optimal ones. Optimal sizes of the Au NPs, pores, and thicknesses are determined by the location of point 3 ( $L=12 \mathrm{~mm}$ ); the structure of mentioned region is presented on Figures 2(c) and 3 (point 3). Therefore, using the point location on the film with the thickness, sizes of the Au NPs, and pores gradients one can easily determine the optimal values for the highest enhancement of the SERS signal.

Figure 6 presents the following spectra: SERS spectra of the Rhodamine $6 \mathrm{G}$ molecules with the concentration $10^{-10} \mathrm{Mol} / \mathrm{L}$ placed on the prepared SERS substrate (3), SERS spectra for the Rhodamine $6 \mathrm{G}$ molecules with the concentration $10^{-7} \mathrm{Mol} / \mathrm{L}$ placed on the prepared SERS substrate (1) and on the SERS substrate with Au film deposited using the thermal evaporation in the vacuum (2), and Raman spectrum of the Rhodamine $6 \mathrm{G}$ molecules with the concentration 


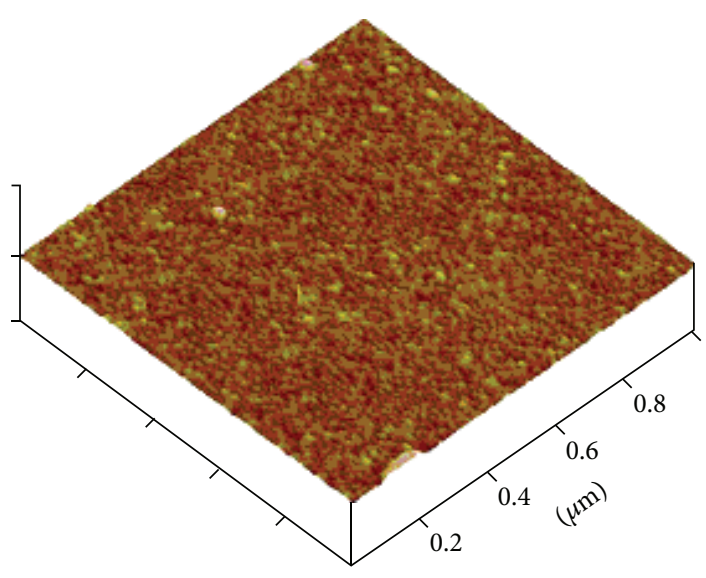

$x: 0.200 \mu \mathrm{m} / \mathrm{div}$

$z: 50.000 \mathrm{~nm} / \mathrm{div}$

(a)

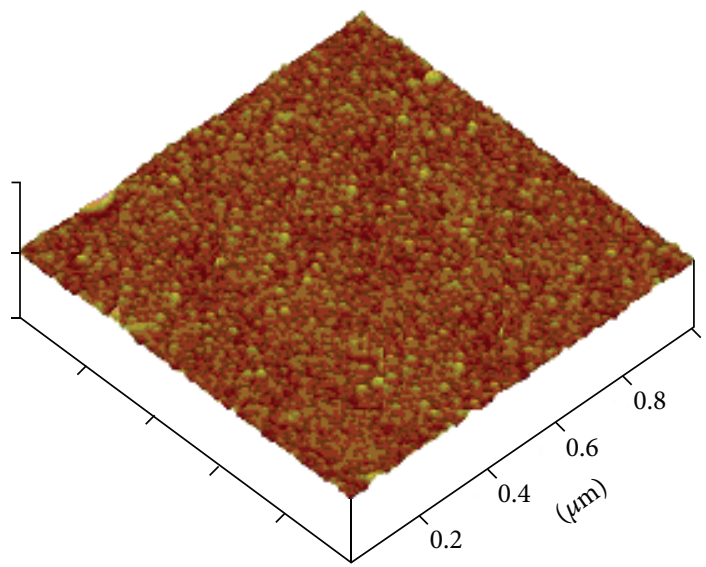

$x: 0.200 \mu \mathrm{m} / \mathrm{div}$

$z: 50.000 \mathrm{~nm} / \mathrm{div}$

(c)

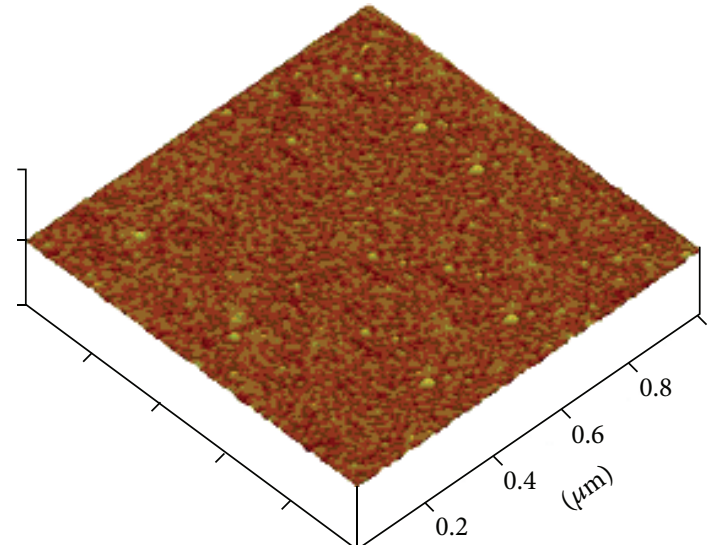

$x: 0.200 \mu \mathrm{m} / \mathrm{div}$

$z: 50.000 \mathrm{~nm} / \mathrm{div}$

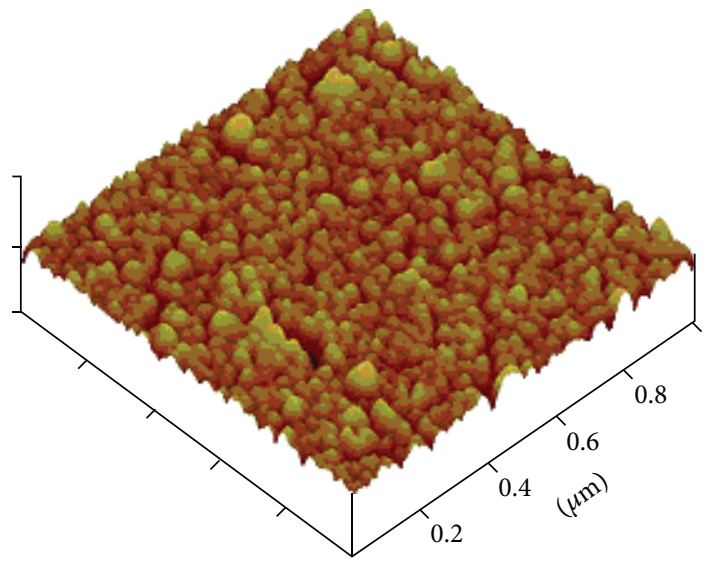

$x: 0.200 \mu \mathrm{m} / \mathrm{div}$

$z: 50.000 \mathrm{~nm} / \mathrm{div}$

(d)

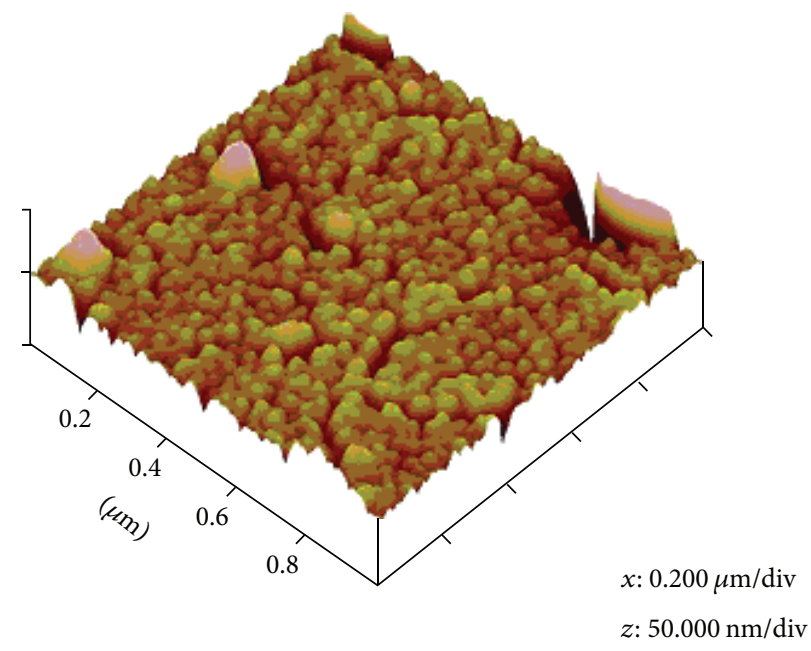

(e)

Figure 2: The AFM images in the five points of the por-Au film on the distance from the erosion torch axis $L$ (mm): 22 (a), 17 (b), 12 (c), 6 (d), and 2 (e). The deposition regime was the following: one pulse energy $5 \mathrm{~J} / \mathrm{cm}^{2}$, number of the laser pulses $N=30000$, and argon pressure $100 \mathrm{~Pa}$. 

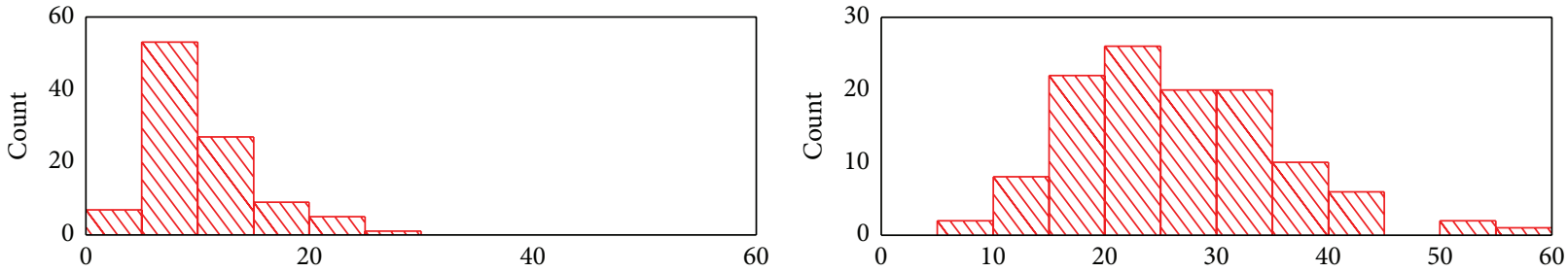

AV Point 5

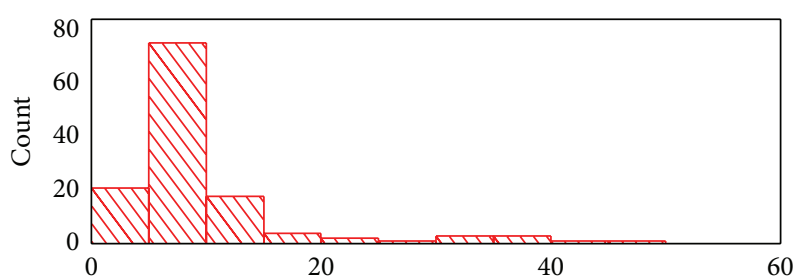

NIV Point 5

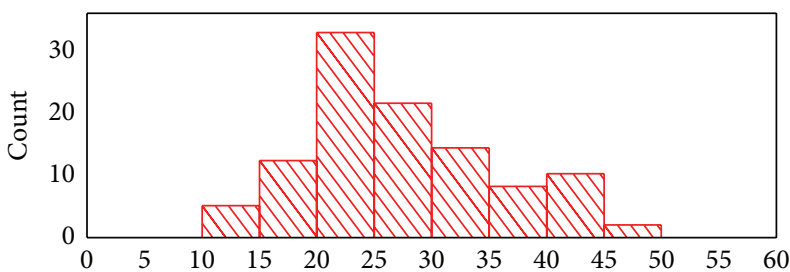

NIV Point 4

NIV Point 4
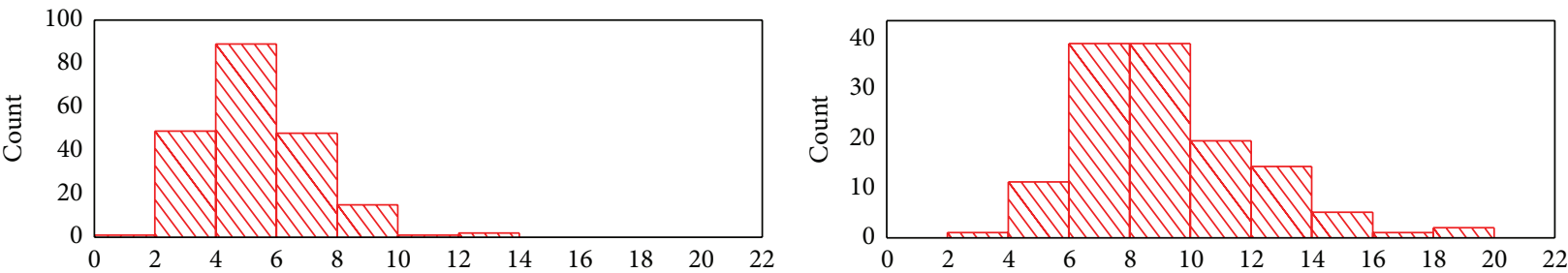

NIV Point 3

NIV Point 3
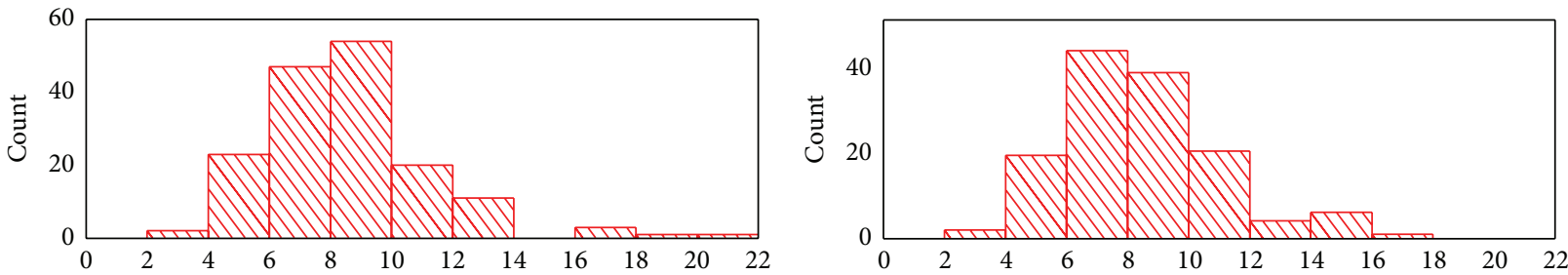

AV Point 2

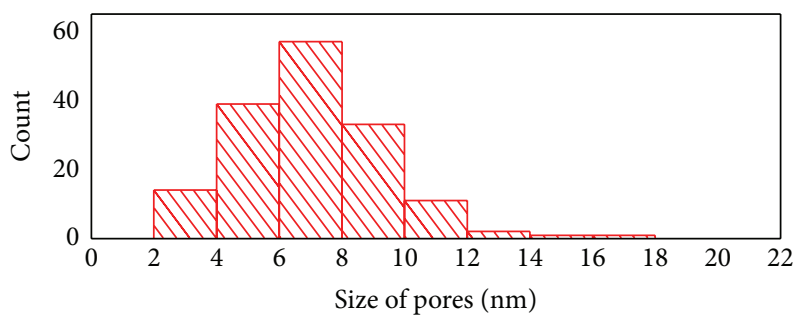

NVP Point 2

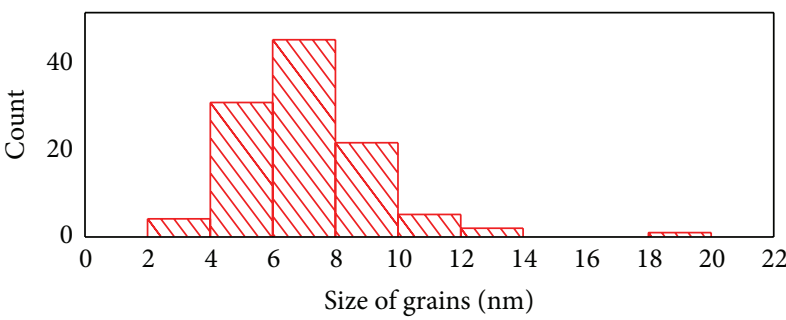

NIV Point 1

NIV Point 1

FIGURE 3: The histograms of the distribution of the Au seeds sizes and pores for five points of por-Au film on the distance from the erosion torch axis $L(\mathrm{~mm}): 2,6,12,17$, and 22 (from top to down). The deposition regime was the following: one pulse energy $5 \mathrm{~J} / \mathrm{cm}^{2}$, number of the laser pulses $N=30000$, and argon pressure $100 \mathrm{~Pa}$. 


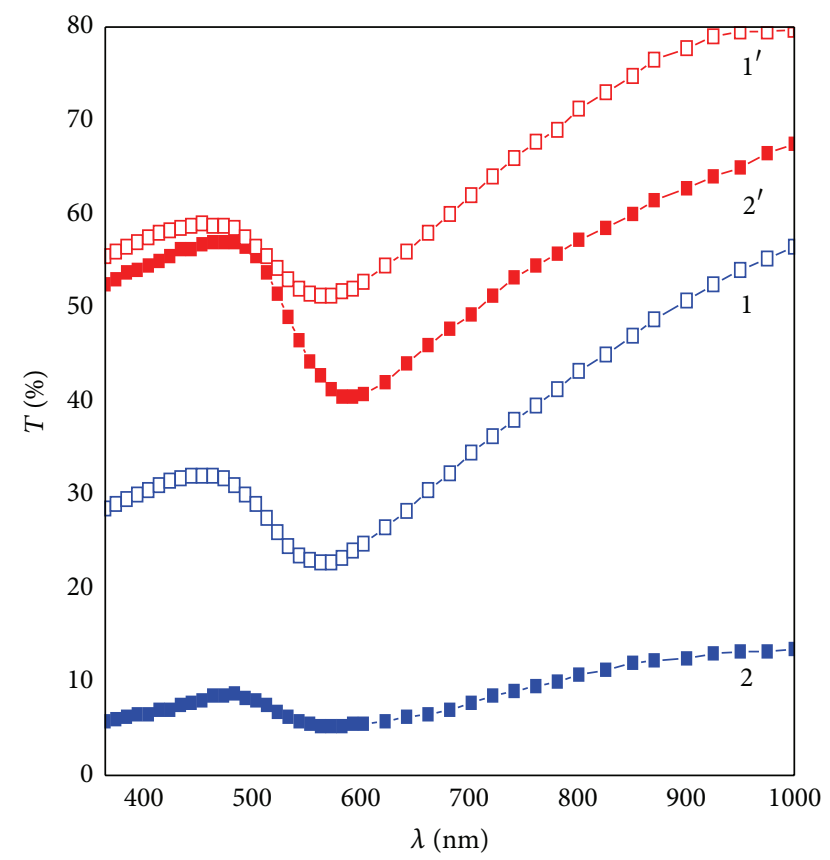

FIGURE 4: The transmittance spectra of the por-Au films prepared at the one pulse energy $5 \mathrm{~J} / \mathrm{cm}^{2}$ and the number of the laser pulses $N=30000$ measured at various argon pressures: $1,1^{\prime}: 13.5 \mathrm{~Pa}$ and 2 , $2^{\prime}: 100 \mathrm{~Pa}$, and distances $L: 1,2: 5 \mathrm{~mm}$ and $1^{\prime}, 2^{\prime}: 15 \mathrm{~mm}$.

$10^{-3} \mathrm{Mol} / \mathrm{L}$ on the glass. Firstly, the possibility of the identification of Rhodamine $6 \mathrm{G}$ molecules with the concentration $10^{-10} \mathrm{Mol} / \mathrm{L}$ is presented. It is important to note that some bands of the studied analyte are detected even at $10^{-11} \mathrm{Mol} / \mathrm{L}$ which is the detection limit. Secondly, the evaluation of the enhancement indicates that the $\mathrm{EF}$ is within the range of $10^{3}$ up to $10^{8}$. In our case it was determined from the expression

$$
F=\frac{I_{1}}{I_{2}} \cdot \frac{N_{2}}{N_{1}}
$$

where $I_{1}$ and $I_{2}$ are integral peaks intensities in the Rhodamine spectra on the prepared SERS substrates and on the glass and $N_{1}$ and $N_{2}$ are Rhodamine concentrations, respectively. The values of enhancement factors on the studied SERS substrates for the various R6G concentrations $10^{-5}, 10^{-7}, 10^{-9}$, and $10^{-10} \mathrm{Mol} / \mathrm{L}$ were $3.1 \times 10^{3}, 7.2 \times 10^{4}, 5.2 \times 10^{6}$, and $3.9 \times$ $10^{7}$, correspondingly, for one of the optimal points of por- $\mathrm{Au}$ film. The parameters of the SERS substrates based on por-Au film prepared using the developed PLD method are equal to the world's best samples.

\section{Conclusions}

The method of the preparation of SERS substrates on the base of porous Au films was developed on the base of pulsed laser deposition technique using the back low-energy flux of erosion torch particles on the substrate placed at the target plain. Using the developed method the nanocomposite porous films with Au NPs array were prepared. The enhancement factor $4 \times 10^{7}$ was ascertained for SERS substrates based on the films with Au NPs array for the detection of the Rhodamine

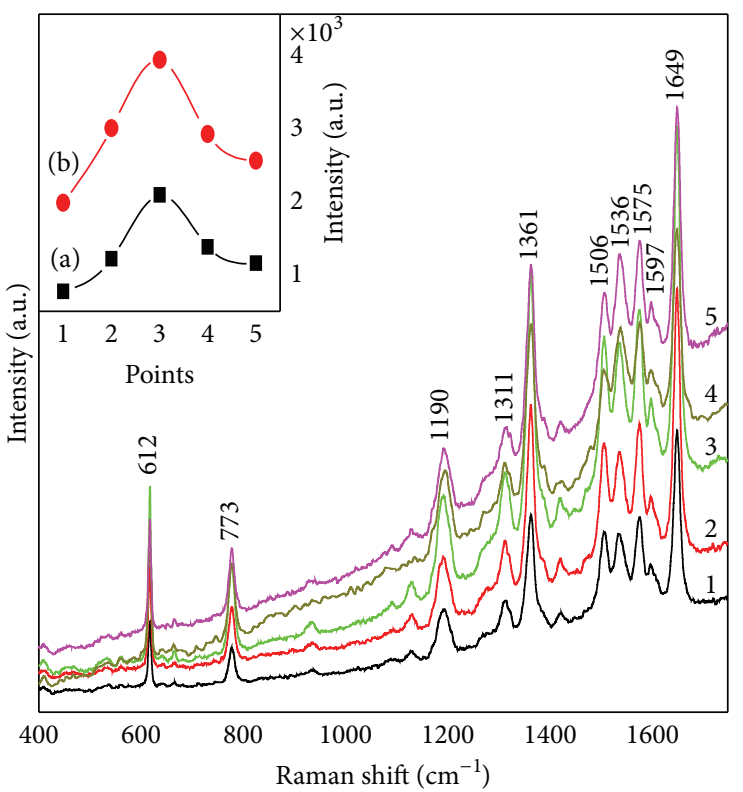

FIgURE 5: The SERS spectra of $\mathrm{R} 6 \mathrm{G} 10^{-7} \mathrm{Mol} / \mathrm{L}$ on the prepared SERS substrates based on the por-Au films in five points with thickness increase from top to down. The corresponding distances from the torch axis are $22,17,12,6$, and $2 \mathrm{~mm}$. In the insertion the dependencies of the SERS signal intensity at $612 \mathrm{~cm}^{-1}$ (a) and $1649 \mathrm{~cm}^{-1}$ (b) for the mentioned five points are shown.

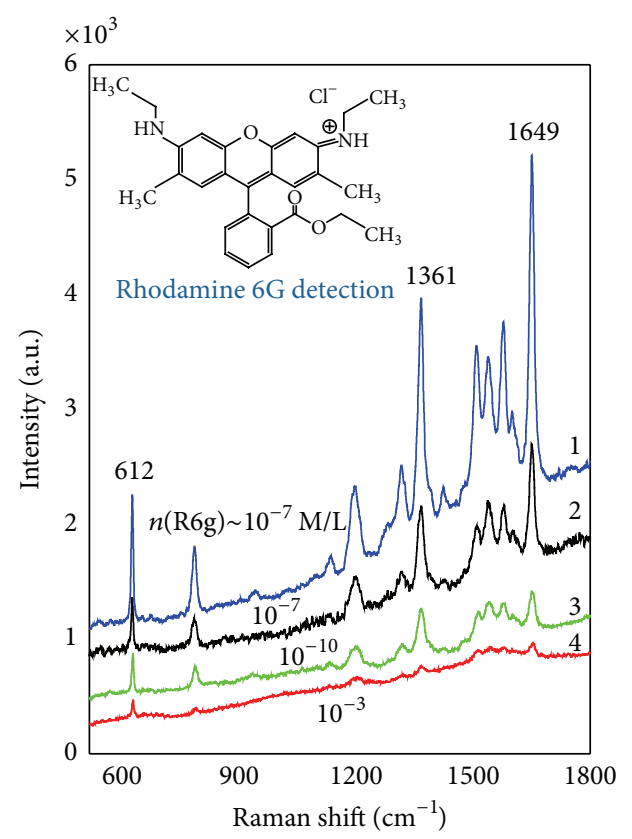

FIgURE 6: The SERS spectra of the Rhodamine 6G molecules placed on the prepared substrates with various concentrations: $10^{-7} \mathrm{Mol} / \mathrm{L}$ (1) and $10^{-10} \mathrm{Mol} / \mathrm{L}$ (3). The SERS spectrum of Rhodamine $6 \mathrm{G}$ molecules with the concentration $10^{-7} \mathrm{Mol} / \mathrm{L}$ placed on the gold film deposited by thermal evaporation in vacuum is shown as curve 3. The SERS spectrum of Rhodamine $6 \mathrm{G}$ molecules with the concentration $10^{-3} \mathrm{Mol} / \mathrm{L}$ placed on glass is shown as curve 4 . 
6G molecules with concentration of $10^{-10} \mathrm{Mol} / \mathrm{L}$. The high enhancement parameters are caused by the high internal surface for analyte and by "hot spots" existence in the pores. Herewith, the developed method is characterized by simple processes and cheap apparatus for the realization.

\section{Acknowledgment}

This work was supported by the Department of Special Training of National Academy of Sciences of Ukraine at Kyiv University, Project no. 0014U003874.

\section{Conflict of Interests}

The authors declare that there is no conflict of interests regarding the publication of this paper.

\section{References}

[1] S. Abalde-Cela, P. Aldeanueva-Potel, C. Mateo-Mateo, L. Rodríguez-Lorenzo, R. A. Alvarez-Puebla, and L. M. LizMarzán, "Surface-enhanced Raman scattering biomedical applications of plasmonic colloidal particles," Journal of the Royal Society Interface, vol. 7, no. 4, pp. S435-S450, 2010.

[2] S. L. Kleinman, E. Ringe, N. Valley et al., "Single-molecule surface-enhanced raman spectroscopy of crystal violet isotopologues: theory and experiment," Journal of the American Chemical Society, vol. 133, no. 11, pp. 4115-4122, 2011.

[3] E. C. Le Ru, M. Meyer, and P. G. Etchegoin, "Proof of singlemolecule sensitivity in Surface Enhanced Raman Scattering (SERS) by means of a two-analyte technique," The Journal of Physical Chemistry B, vol. 110, no. 4, pp. 1944-1948, 2006.

[4] N. P. W. Pieczonka, G. Moula, and R. F. Aroca, "SERRS for single-molecule detection of dye-labeled phospholipids in Langmuir-Blodgett monolayers," Langmuir, vol. 25, no. 19, pp. 11261-11264, 2009.

[5] L. Rodríguez-Lorenzo, R. A. Álvarez-Puebla, I. Pastoriza-Santos et al., "Zeptomol detection through controlled ultrasensitive surface-enhanced raman scattering," Journal of the American Chemical Society, vol. 131, no. 13, pp. 4616-4618, 2009.

[6] B. Sharma, R. R. Frontiera, A.-I. Henry, E. Ringe, and R. P. van Duyne, "SERS: materials, applications, and the future," Materials Today, vol. 15, no. 1-2, pp. 16-25, 2012.

[7] L.-B. Luo, L.-M. Chen, M.-L. Zhang et al., "Surface-enhanced raman scattering from uniform gold and silver nanoparticlecoated substrates," The Journal of Physical Chemistry C, vol. 113, no. 21, pp. 9191-9196, 2009.

[8] A. Kumar, B. Mazinder Boruah, and X.-J. Liang, "Gold nanoparticles: promising nanomaterials for the diagnosis of cancer and HIV/AIDS," Journal of Nanomaterials, vol. 2011, Article ID 202187, 17 pages, 2011.

[9] C.-W. Hsieh, P.-Y. Lin, and S. Hsieh, "Improved surfaceenhanced Raman scattering of insulin fibril templated colloidal gold nanoparticles on silicon," Journal of Nanophotonics, vol. 6, no. 1, Article ID 063501, 2012.

[10] G. Herrera, A. Padilla, and S. Hernandez-Rivera, "Surface Enhanced Raman Scattering (SERS) studies of gold and silver nanoparticles prepared by laser ablation," Nanomaterials, vol. 3, no. 1, pp. 158-172, 2013.

[11] Y. Jing, H. Wang, X. Chen, X. Wang, H. Wei, and Z. Guo, "Pulsed laser deposited Ag nanoparticles on nickel hydroxide nanosheet arrays for highly sensitive surface-enhanced Raman scattering spectroscopy," Applied Surface Science, vol. 316, pp. 66-71, 2014.

[12] E. Le Ru and P. Etchegoin, Principles of Surface Enhanced Raman Spectroscopy and Related Plasmonic Effects, Elsevier, Wellington, New Zealand, 2009.

[13] M. K. Fan, G. F. S. Andrade, and A. G. Brolo, "A review on the fabrication of substrates for surface enhanced Raman spectroscopy and their applications in analytical chemistry," Analytica Chimica Acta, vol. 693, no. 1-2, pp. 7-25, 2011.

[14] Y. Lu, G. Xue, and J. Dong, " $\mathrm{HNO}_{3}$ etched silver foil as an effective substrate for surface-enhanced Raman scattering (SERS) analysis," Applied Surface Science, vol. 68, no. 4, pp. 485489, 1993.

[15] C. Peng, Y. Song, G. Wei, W. Zhang, Z. Li, and W.-F. Dong, "Self-assembly of $\lambda$-DNA networks/Ag nanoparticles: hybrid architecture and active-SERS substrate," Journal of Colloid and Interface Science, vol. 317, no. 1, pp. 183-190, 2008.

[16] G. Kostovski, D. J. White, A. Mitchell, M. W. Austin, and P. R. Stoddart, "Nanoimprinted optical fibres: biotemplated nanostructures for SERS sensing," Biosensors and Bioelectronics, vol. 24, no. 5, pp. 1531-1535, 2009.

[17] L. H. Qian, X. Q. Yan, T. Fujita, A. Inoue, and M. W. Chen, "Surface enhanced Raman scattering of nanoporous gold: smaller pore sizes stronger enhancements," Applied Physics Letters, vol. 90, no. 15, Article ID 153120, 2007.

[18] H. W. Wang, Y. L. Wang, and X. F. Wang, "Pulsed laser deposition of large-area manganese oxide nanosheet arrays for high-rate supercapacitors," New Journal of Chemistry, vol. 37, no. 4, pp. 869-872, 2013.

[19] H. W. Wang, Y. L. Wang, and X. F. Wang, "Pulsed laser deposition of the porous nickel oxide thin film at room temperature for high-rate pseudocapacitive energy storage," Electrochemistry Communications, vol. 18, no. 1, pp. 92-95, 2012.

[20] E. B. Kaganovich, S. A. Kravchenko, L. S. Maksimenko et al., "Polarization properties of porous gold and silver films," Optics and Spectroscopy, vol. 110, no. 4, pp. 513-521, 2011 (Russian).

[21] E. B. Kaganovich, I. M. Krishchenko, E. G. Manoilov et al., "Structural and optical properties of gold and silver porous films prepared by pulsed laser deposition in vacuum," Nanosystems, Nanomaterials, Nanotechnologies, vol. 10, article 859, 2012 (Russian).

[22] V. P. Kladko, O. Y. Gudymenko, S. B. Kriviy et al., "Reflectometry study of nanoporous films with arrays gold nanoparticles," Ukrainian Journal of Physics, vol. 59, no. 9, pp. 915-921, 2014.

[23] N. R. Agarwal, F. Neri, S. Trusso, A. Lucotti, and P. M. Ossi, "Au nanoparticle arrays produced by pulsed laser deposition for Surface Enhanced Raman Spectroscopy," Applied Surface Science, vol. 258, no. 23, pp. 9148-9152, 2012. 

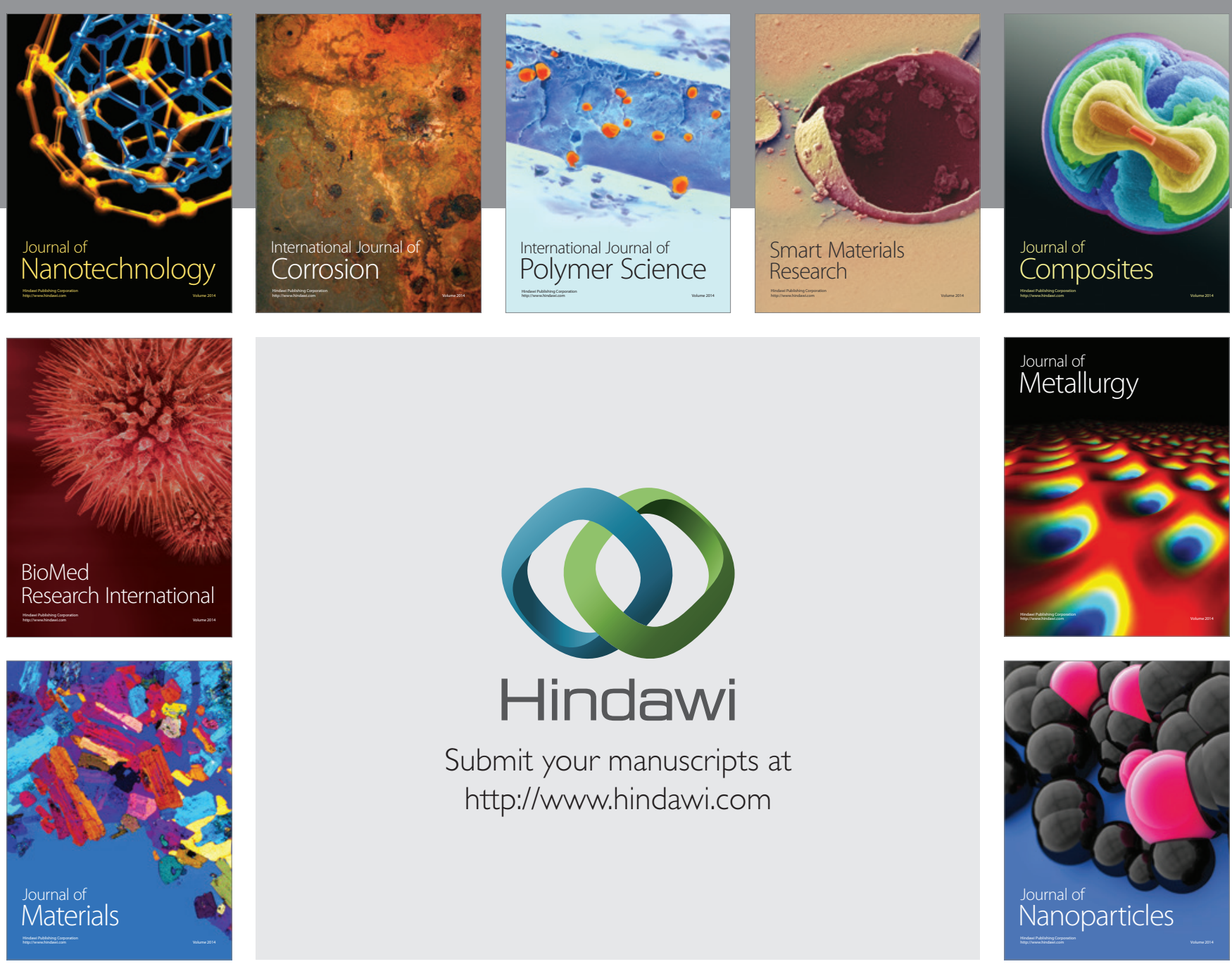

Submit your manuscripts at http://www.hindawi.com
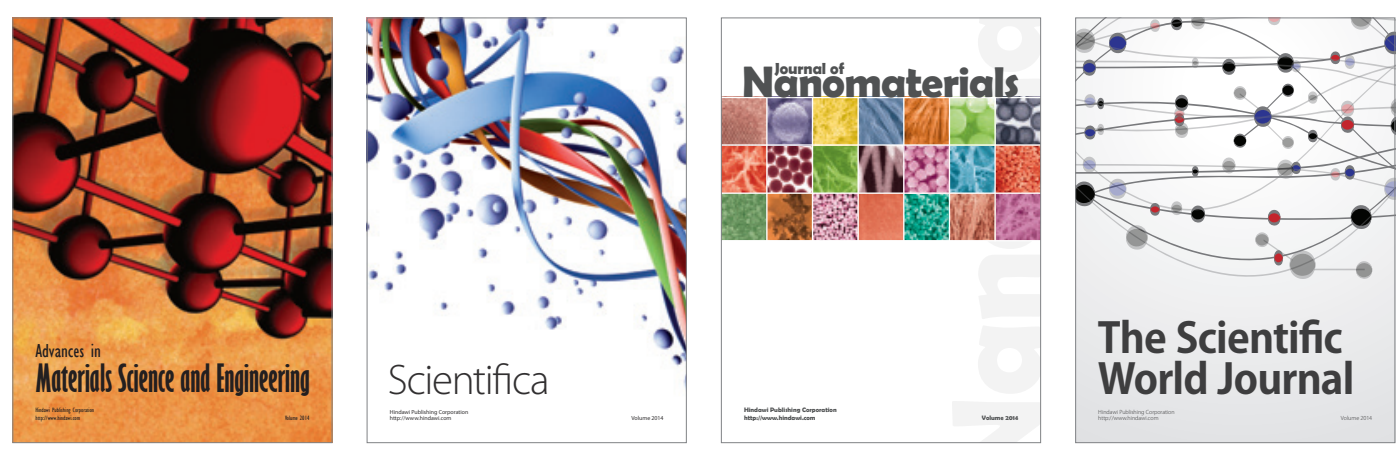

\section{The Scientific World Journal}
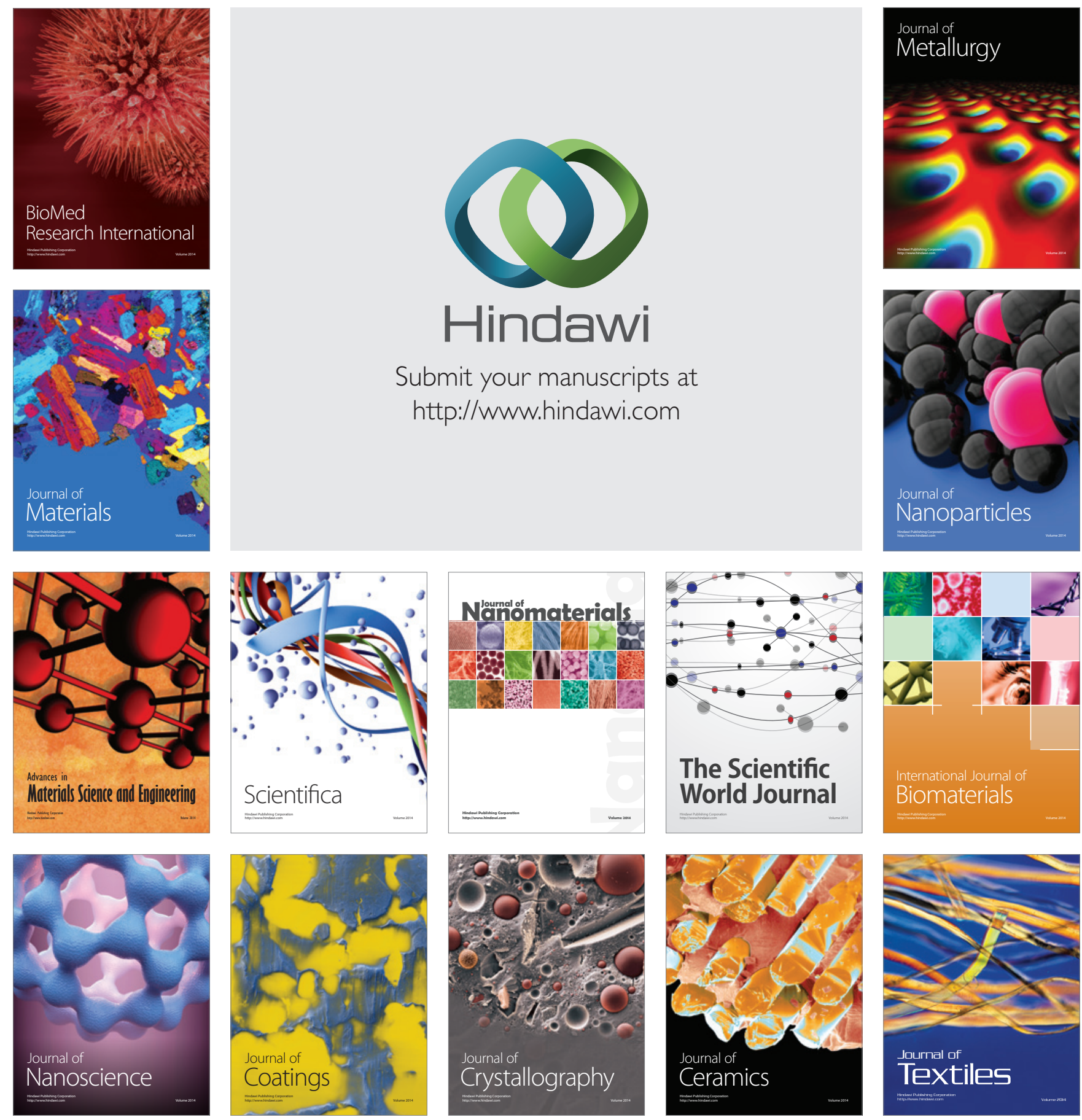